\title{
Grasping in the pigeon (Columba livia): Stimulus control during conditioned and consummatory responses
}

\author{
BRENT C. LaMON and H. PHILIP ZEIGLER \\ American Museum of Natural History, New York, New York \\ and Biopsychology Program, Hunter College of the City University of New York, New York
}

\begin{abstract}
Control of beak opening (gape) and peck location was examined in pigeons. Feeding pecks showed accurate guidance that positioned the seed between the beaks. At the moment of contact with the seed, gape was proportional to seed diameter, although pecks with gape less than seed diameter were more frequent following an increase in seed size during a meal. There were no substantial differences between pigeons trained to keypeck with autoshaping and those trained with operant conditioning procedures. With either procedure, water reinforcement produced keypecks with the beak closed; seed reinforcers of different sizes produced means for gape proportional to the seed diameters. Black or white circular stimuli of different sizes projected as conditioning signals had little influence upon gape, but a greater percentage of responses was directed to white stimuli. These results indicate that visual stimuli elicit and orient the peck, whereas the adjustment of gape also involves the somatosensory stimuli provided during previous experience with a particular reinforcer or food type.
\end{abstract}

The beak of a bird is involved in a variety of behaviors, including eating and drinking, manipulation of nonfood objects (e.g., nest materials), care of the body surface (preening), and agonistic behavior. Considered as an effector organ, the avian beak has functions analogous to those of the hand. Indeed, during grasping the upper and lower beaks operate like the primate thumb and forefinger (Beecher, 1951). The complexity of such behaviors requires a system capable of precise motor organization. Moreover, as a component of both conditioned keypecks and consummatory responses, beak movements provide an important behavioral parameter for comparisons of conditioned and consummatory response forms. We have therefore begun to investigate the sensorimotor control of beak movements by examining the grasping behavior of the pigeon.

Grasping is one of four components of the pigeon's feeding behavior sequence: pecking, grasping, mandibulation, and swallowing (Zeigler, 1976; Zweers, 1982b). High-speed cinematographic analyses indicate that grasping is integrated into the pecking response and may be divided into two distinct phases: beak opening and

This research was supported by N. I. H. Grant MH-37219, Research Scientist Award MH-00320 (H.P.Z.) and Training Grant MH-15341. The authors wish to thank Professor John VanLaer for assistance with the statistical analysis. B. C. LaMon is currently an N. I. H. Postdoctoral Fellow at the Department of Zoology, University of California, Berkeley. Requests for reprints should be sent to $H$. P. Zeigler, West Laboratories, Department of Ornithology, American Museum of Natural History, Central Park West at 79th St., New York, NY 10024. closing-grasping. Beak opening begins about $25-30 \mathrm{msec}$ prior to contact with the seed or substrate, and coincides with the downward movement of the head and eye closure. Immediately prior to beak contact, the eyes are almost closed and the mouth is open. The beak closing phase is initiated at contact and normally terminates with the seed held firmly between the tips of the mandible and maxilla (Zeigler, Levitt, \& Levine, 1980). These beak movements are also combined with adjustments of posture and neck extension that provide accurate control of peck location (Zweers, 1982b).

A preliminary analysis of beak movements during eating reports that the amount of beak opening (gape) immediately prior to contact with the seed varies with seed size across a range that parallels the pigeon's normal diet (Zeigler et al., 1980). This adjustment of gape indicates that beak movements during eating involve sensory control by specific properties of the food stimuli. During drinking, the beak does not open until the beak tips are immersed in water (Klein, LaMon, \& Zeigler, 1983; Zweers, 1982a).

Observations of conditioned keypecking with food or water reinforcers also reveal that under both operant (Spetch, Wilkie, \& Skelton, 1981; Wolin, 1968) and Pavlovian (H. Jenkins \& Moore, 1973) procedures keypecks are similar in form to eating or drinking responses. Based on observers' subjective ratings of response topography, as well as on measures of keypeck force and duration, these studies conclude that the form of the conditioned response was largely determined by the type of reinforcer. Given the importance of this conclusion for conditioning theory (e.g., H. Jenkins \& Moore, 
1973; Williams, 1981; Woodruff \& Williams, 1976), it should be noted that the comparison of the keypeck to the consummatory response has been based primarily upon indirect and qualitative measures of pecking topography. No quantitative measures of gape during conditioned keypecking are currently available, nor are there studies of the control of gape by other features of the conditioning situation, such as the physical properties of the signal (response key).

Our previous studies, in which grasping was examined within the context of the pigeon's feeding behavior, revealed a relationship between seed size and gape. The present experiments were designed to replicate and extend those observations in order to clarify the factors producing such beak movements. In this study, we have isolated and quantified the beak-opening phase of the peck, examined certain aspects of its sensory control, and extended our observations to conditioning situations.

\section{EXPERIMENT 1}

The data on grasping reported in Zeigler et al. (1980) were obtained using a cinematographic procedure that would be unnecessarily costly in both time and film in the present instance inasmuch as the data of interest (gape size at a specific time) would be contained on a single frame of film and the remaining frames would be superfluous. Furthermore, a motion picture procedure does not provide for triggering the camera at precisely the same point in each eating response sequence, a necessary condition for accurate comparison of gape measurements. The primary aim of the first experiment was to replicate the function relating gape size to seed size using an improved measurement procedure-a greater number of birds and observations per bird. In addition, we examined the effect of experience eating different seed sizes on subsequent grasping responses.

\section{Method}

\section{Subjects}

Ten experimentally naive adult male White Carneaux pigeons were obtained from a commercial breeder, housed in individual cages, and maintained in an animal room (12-h/12-h light/dark cycle; ambient temperature $21-27^{\circ} \mathrm{C}$ ). During testing, the birds were maintained at about $80 \%$ of free-feeding weight with a daily ration of approximately $20 \mathrm{~g}$ of milo.

\section{Apparatus}

The experimental chamber was $30 \times 38 \times 42 \mathrm{~cm}$ high, with a wire grid floor. One wall and the ceiling were clear Plexiglas, and the remaining walls and floor were painted flat black to reduce reflection. In a corner next to the Plexiglas wall, a $25-\mathrm{mm}$ square response key was mounted in the floor $4 \mathrm{~cm}$ away from the adjacent walls. The opening to a hopper (Lehigh Valley) was centered $3 \mathrm{~cm}$ above the floor on the black wall adjacent to the response key. For photographic purposes, the chamber was placed in a small, lightproof enclosure. Chamber illumination was provided by a safelight (15-W) with a Kodak-1A red filter mounted $1 \mathrm{~m}$ above the chamber.
The pecking surface of the response key was frosted acrylic, which allowed for the rear projection of various signal stimuli by a Kodak Carousel slide projector mounted beneath the chamber. The response key incorporated a Lafayette Instruments Force Transducer (No. 76613), whose output was monitored by a voltage comparator that provided logic pulses for responses that exceeded a theshold value of $5 \mathrm{~g}$.

A photographic system provided a size-calibrated image of the pigeon's head at the moment of key contact. A Photographic Alliance $35-\mathrm{mm}$ instrumentation camera was used with a Nikon $55-\mathrm{mm}$ macro lens and polarizing filter. Because of the delay imposed by shutter opening (about $10 \mathrm{msec}$ ) and the limited film capacities of conventional reflex-type cameras, a shutterless camera was used with Kodak 2495 Orthochromatic film (blue sensitive, $35 \mathrm{~mm} \times 150 \mathrm{ft}$ ). This film was not exposed by the ambient illumination of the safelight and exposures were obtained by a flash from a General Radio strobe light. The strobe was activated at the moment of key contact by a solidstate relay controlled by the voltage comparator/force transducer. Because the camera required $0.5 \mathrm{sec}$ to advance one frame, any pecks occurring during the film advance were not recorded. Data for gape (distance between the beak tips) and location of each peck were taken from the size-calibrated photonegatives using a Realistic microfilm reader with $22 \times$ magnification.

\section{Procedure}

Birds were adapted to the testing chamber until they would readily approach and eat seeds placed on the response key. For testing, seeds of a single type were placed on the key and, when eaten, replaced until at least 20 pecks for each seed type had been photographed for each subject. Three seed types were presented in the following order for all birds; milo, $2-5 \mathrm{~mm}$; peas, $5-8 \mathrm{~mm}$; and garbanzo beans, $8-12 \mathrm{~mm}$.

\section{Results}

Figure 1 presents a photograph that illustrates the characteristic topography of pecks made at the seeds used in this experiment. The beak is open at the moment of contact and gape size is slightly larger than seed diameter. The location of the peck shows accurate guidance so that the seed is positioned between the beak tips.

Figure 2 plots gape size as a function of seed diameter for individual grasping responses obtained from all subjects and each of the seed types. The diagonal line shows the interbeak tip distance necessary to match various seed diameters. Points falling below this line indicate pecks for which gape was less than the diameter of the seed. It is clear that gape increases with seed size and that, for the majority of pecks, beak opening was slightly larger than seed diameter. It should be noted, however, that there was a substantial population of pecks for which gape size was less than seed diameter and these errors increased with seed size.

The difference between emitted gape and target seed diameter was measured for a series of successive pecking responses in order to examine the effects of experience upon the extent of gape error. Figure 3 presents for each of the three seed sizes the mean differences between gape and seed diameter across a series of successive re- 


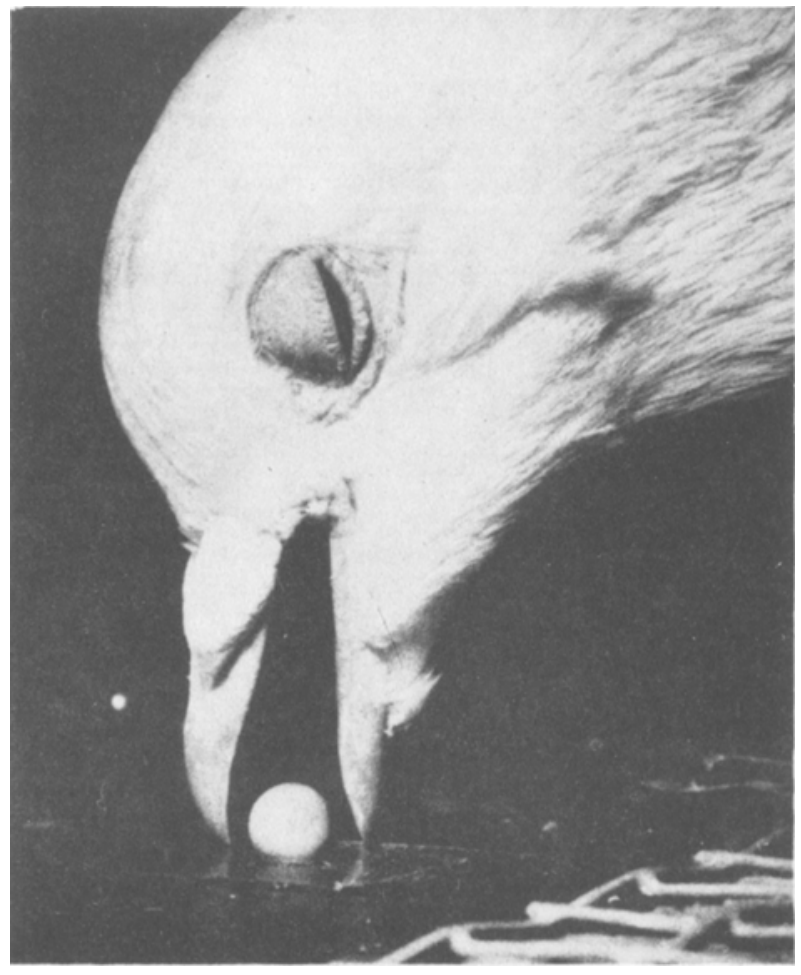

Figure 1. Photograph shows characteristic topography of pecks made at the seeds used in the experiments.

sponses. Difference scores from nine subjects were averaged for blocks of two successive pecks; data for one subject were unavailable due to equipment malfunction. The number of pecking errors (gape $<$ seed diameter)

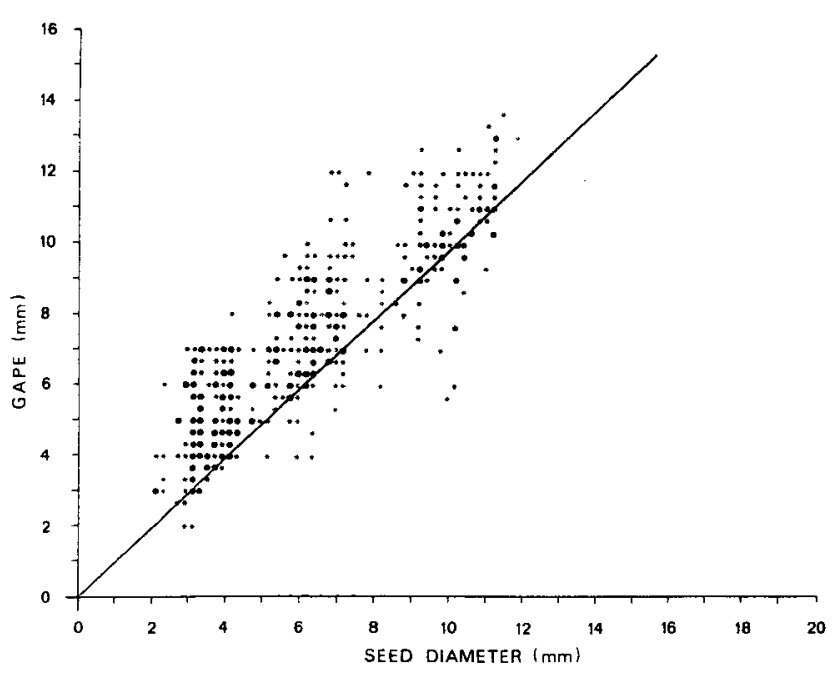

Figure 2. Gape size (in millimeters) as a function of seed diameter (in millimeters) for individual feeding responses. The diagonal line shows the interbeak tip distance (gape) necessary to match various seed diameters. Stars indicate single responses, and solid circles indicate coordinates for which there was more than one response. Figure represents data for 545 responses. is indicated for each of the means. With milo, always the first seeds tested, gape size was typically larger than seed size beginning with the very first pecks. The least number of errors was obtained with milo, which was the only food given in the home cage. For peas, gape size for many birds was less than seed size during the first few responses, but was rapidly adjusted. By the second block, mean gape for peas was greater than seed diameter and remained so throughout the remaining trials. When tested with garbanzo, many birds again produced gapes substantially below seed size. While these errors decreased gradually over successive responses, the amount of gape overshoot (larger than seed diameter) for these large seeds tended to be less than for milo and peas.

\section{Discussion}

These data indicate that during feeding gape size at the moment of contact with the seed is proportional to seed diameter across a range of seed sizes from 2 to $12 \mathrm{~mm}$. However, for the smaller sizes, beak opening was typically larger than seed diameter, while for larger sizes gape may be insufficient. Pigeons opening their mouths to grasp seed thus show both overshooting and errors in beak opening during feeding responses.

The overshooting of gape size may actually increase the efficiency of pecking responses because it tends to maximize the probability that the seed will be positioned between the two beaks rather than be stuck and displaced by the beak tips-a frequent cause of grasping errors in both normal birds and birds with lesions of brain structures controlling mouth opening (Levine \& Zeigler, 1981). Pecks with gape less than seed diameter tend to be more frequent following an increase in seed size, and these grasping errors decrease with repeated pecks until gape is slightly larger than the diameter of the seeds. This pattern of gape errors followed by improvement in grasping performance suggests a role for experiential factors in the control of gape.

Several observations indicate that the adjustment of gape size involves an open control system (feed forward) in which variations in response do not depend upon continuous feedback from the eliciting stimulus (Mittelstaedt, 1962). The first is the extreme brevity of the peck, which allows little time for feedback adjustment. Furthermore, the gape measurements reflect the amount of beak opening prior to (Zeigler et al., 1980) or at the moment of contact with the seed (Experiment 1) and at the end of a period of continuous eye closure. The amount of beak opening therefore appears to be independent of visual or tactile feedback generated during the pecking response. Moreover, observations of gape size with repeated pecks indicate that adjustments of beak opening were not produced solely on the basis of visual information available immediately prior to peck initiation. When seed size increased abruptly during a meal (from milo to pea and from pea to garbanzo) gape size did not immediately reflect the stimulus properties (size) of the 


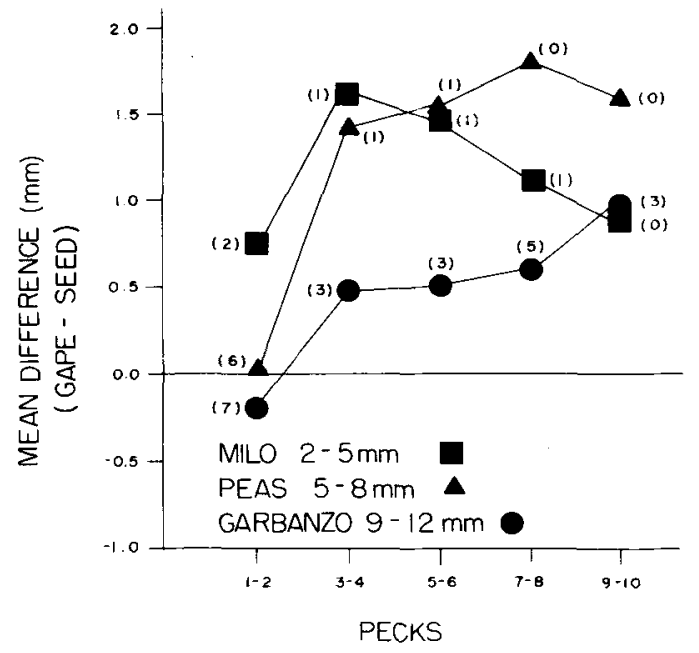

Figure 3. Mean differences (gape minus seed diameter) across blocks of two successive responses for three sizes of seed. Data are from nine subjects (18 pecks/block). Also shown, in parentheses, are the number of gape errors (gape < seed diameter) included in each of the means. Each subject made a series of at least 20 pecks with each seed size, and seed types were tested in order of increasing size for all subjects.

new seed, but appears to have been biased by the preceding size series. This suggests that, following a series of seeds of the same general size, the determination of gape involves a motor "set" generated by previous experience with specific seed sizes.

\section{EXPERIMENT 2}

Investigations of conditioned response form have shown that the topography of keypecks made by pigeons receiving food or water reinforcement is similar to the consummatory responses for eating and drinking (H. Jenkins \& Moore, 1973; Spetch et al., 1981; Wolin, 1968). One feature of the conditioned keypeck used to distinguish between responses for food or water reinforcers was the extent of beak opening; food-reinforced keypecks were characterized as having the beak open, and water-reinforced keypecks as having the beak closed. Incidental observations by Blough (1961) and Moore (1973) also suggest that an adjustment of gape size to stimulus size may be made by pigeons pecking at spots of light projected upon a response key. Thus, the determination of gape in conditioning situations may be influenced by the visual stimulus properties of the response key as well as experience with a particular type of reinforcer. Experiment 2 was designed to explore these possibilities by examining beak opening and peck location for keypecks produced in a test situation in which stimulus properties, deprivation state, reinforcer type, and conditioning paradigms were systematically varied.

\section{Method}

Subjects

For birds receiving food reinforcers, subjects and maintenance procedures were as described for Experiment 1. Ten additional adult White Carneaux pigeons were maintained at $80 \%$ of their ad-lib weights by water deprivation. These birds received water reinforcers during conditioning sessions on alternate days with an additional $20-40 \mathrm{ml}$ of water provided after each session. The group receiving food reinforcers and the group receiving water reinforcers were subdivided, with half the birds from each group randomly assigned to either an autoshaping or an operant conditioning procedure. Due to illness, one bird in the food-reinforcer/autoshaping group did not complete Experiment 2 .

\section{Apparatus}

The chamber and photographic system described for Experiment 1 was used for the conditioning sessions of Experiment 2 . A rear-projection system was used to provide signal stimuli on the response key and either food or $0.5 \mathrm{ml}$ of water was presented in the wall-mounted hopper as reinforcers. Control of signal presentations and reinforcer delivery was achieved with solid-state programming equipment (Lehigh Valley) located in an adjacent room.

\section{Signal Stimuli}

In addition to the illuminated 25 -mm-square response key (hereafter referred to as the plain signal), two sets of circular stimuli were projected on the response key as targets during separate conditioning sessions. One set of signal stimuli were white dots on a black background, and the other set were black dots on a white (illuminated) background. For both conditioning groups that received food reinforcers, circular stimuli of 2-, 4-, 6-, 10-, and 14-mm diameter were used. During each session with these stimuli, all sizes and the plain signal appeared seven times in random order, for a total of 42 trials in each session. For the conditioning groups that received water reinforcers, circular stimuli of $4-, 10-$, and $14-\mathrm{mm}$ diameter were presented, each 10 times in succession for a total of 30 trials per session.

Measurements of gape with respect to the different circular stimuli were made from the size-calibrated photograph of each peck. Since the circular stimuli were projected uniformly in the center of the response key, it was also possible to identify those pecks that were directed to the target stimulus, that is, those with at least one beak tip in contact with or both beak tips centered over the projected stimulus.

\section{Procedure}

Autoshaping procedure. Training with the autoshaping procedure involved a $1-\mathrm{min}$ variable intertrial interval (ITI) with a 6-sec signal followed by $4-\mathrm{sec}$ access to the reinforcer independent of responding. Availability of the reinforcer was signaled by hopper illumination. Training sessions were conducted on alternate days for each subject.

Acquisition training with a plain signal was conducted for a sufficient number of sessions to record at least 100 pecks for each subject. For the food-reinforcer group, these sessions consisted of 40 trials with milo as the reinforcer. There were 20 trials per session for the water-reinforcer group. Training then continued with food (milo) or water reinforcers and the circular signal stimuli; a session with white stimuli was conducted first, followed by a session with black stimuli. For the food-reinforcer group, training was completed with two sessions using a plain signal and peas $(5-8 \mathrm{~mm})$ as the reinforcer.

Operant procedure. The birds were shaped by the method of successive approximations to peck the illuminated response key. Pecks terminated key illumination and were followed by presen- 
tation of the reward (milo or water) in the illuminated hopper for $4 \mathrm{sec}$. Responses to the darkened key were without effect. During shaping, the key was illuminated continuously between reward presentations and periods of key illumination were progressively decreased until signal onset reliably controlled responding. As they acquired pecking, the birds were placed on a discriminated continuous-reinforcement, 6-sec limited hold, variable intertrial interval 1-min reinforcement schedule. The shaping procedure typically required several sessions and was terminated after 15 successive signal illuminations with a response. In order to approximately match both rate of response and density of reinforcement with those of the autoshaping procedure, the response criterion was then increased to a variableratio 3 for the remainder of the experiment (discriminated VR3, limited hold $6 \mathrm{sec}$, variable ITI $1 \mathrm{~min}$ ).

For the operant groups receiving food or water rewards, the number of trials per session and training sequence were the same as for the autoshaping groups. Training with a plain signal was conducted until 100 responses were recorded for each bird. This was followed by sessions with white and then black target stimuli. The food-reward group received two additional sessions with a plain signal and $5-8 \mathrm{~mm}$ peas as the reward.

\section{Results}

Figure 4 plots mean gape as a function of stimulus diameter for conditioning groups recieving food or water reinforcers. For each conditioning group, the data from sessions with white or black signal stimuli are plotted separately. It is clear that variations in the diameter of the signal had relatively little effect upon gape size and that the means for each group fall within a range that was consistent with the type of reinforcer received (cf. Table 1). With food reinforcers, the only effect attributable to stimulus size was found with the operant group pecking white stimuli; here there was a difference between the mean gape values obtained with the smallest and largest stimuli. Although this difference (4.8 vs. $7.7 \mathrm{~mm}$ ) was small in comparison with the range of stimulus diameters ( 2 vs. $14 \mathrm{~mm}$ ), the increase in mean gape with the larger stimulus was seen for every subject $[$ matched $t(4)=4.8, p<.01]$.

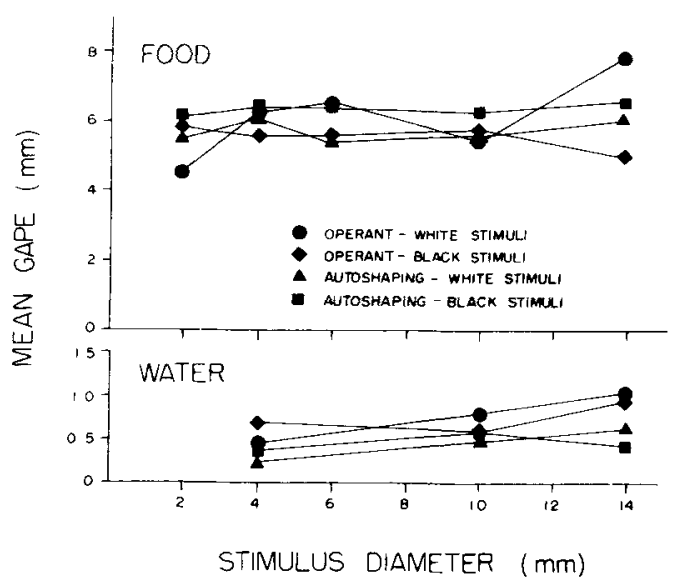

Figure 4. Mean gape (in millimeters) as a function of stimulus diameter (in millimeters) for conditioning groups receiving food or water reinforcers with white or black circular stimuli as the conditioning signal.

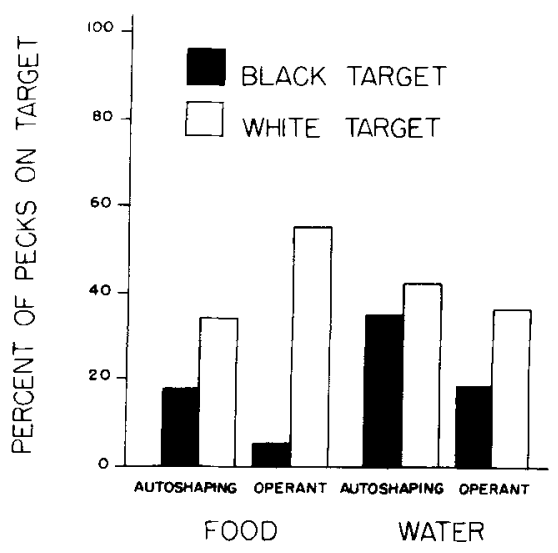

Figure 5. The percentage of pecks directed to the black or white circular stimuli by conditioning groups receiving food or water reinforcers. A response was scored as being directed to the target stimulus if both beak tips were centered over or one beak tip was in contact with the circular stimulus.

For conditioning groups receiving water reinforcers, variation in mean gape across different stimulus diameters was less than $1 \mathrm{~mm}$. With white signals, both conditioning groups showed a trend of increasing gape with larger stimulus size. However, this effect was not statistically significant and there were no consistent trends with black signal stimuli.

Figure 5 shows the percentage of pecks directed at white or black signal stimuli by conditioning groups receiving food or water reinforcers. It is apparent that the circular stimuli did not reliably control peck location with either reinforcer or conditioning paradigm. Among the different conditioning groups the percentage of pecks directed to white and black stimuli varied considerably. However, in each conditioning group a greater percentage of pecks was directed to the white stimuli than to black ones. This difference in the tendency to peck at white and black signals was confirmed by a statistical analysis (Grizzle, Starmer, \& Koch, 1969) of the frequencies of pecks located on and off the target stimuli $\left[\chi^{2}(1)=58.7, p<.001\right]$.

In contrast with the relatively minor effects attributable to variations in the signal stimuli, different types of reinforcer produced substantial changes in gape for conditioned keypecks. Table 1 presents individual and group means for gape size obtained with the plain signal and milo, pea, or water reinforcers. Both conditioning groups that received water reinforcers yielded means that were quite small, confirming that pigeons trained with water reinforcers keypeck with the beak closed. The birds receiving food reinforcers made keypecks with the beak open. Moreover, it is of particular importance that, with either conditioning procedure, the larger pea reinforcer produced keypecks with wider gape than did the milo reinforcer. Figure 6 compares the group means for gape produced with milo and pea reinforcers and shows that these means were of approximately the same 
Table 1

Mean Gape (in Millimeters) With Different Reinforcers

\begin{tabular}{cccc}
\hline & \multicolumn{3}{c}{ Reinforcer } \\
\cline { 2 - 3 } Subject & Milo & Pea & Water \\
\hline Operant & & & \\
251 & 5.3 & $9.2^{*}$ & \\
255 & 5.2 & $9.7^{*}$ & \\
262 & 7.2 & $7.3^{*}$ & \\
281 & 4.3 & $9.3^{*}$ & \\
774 & $5.6^{*}$ & \\
Group & $8^{*}$ & \\
686 & & & 0.3 \\
688 & & & 0.5 \\
694 & & & 0.6 \\
696 & & & 1.6 \\
762 & & & 0.6 \\
Group & & & 0.7 \\
Autoshaping & & & \\
237 & 3.1 & $5.0^{*}$ & \\
247 & 3.1 & 3.2 & \\
282 & 7.9 & $9.3^{*}$ & \\
812 & 5.2 & $6.6^{*}$ & \\
Group & 4.8 & $6.0^{*}$ & \\
666 & & & 0.4 \\
698 & & & 0.3 \\
763 & & & 0.0 \\
719 & & & 0.1 \\
765 & & & \\
Group & & & \\
\hline
\end{tabular}

Note-For individual comparisons of mean gape with milo versus pea reinforcers, $t$ statistics were calculated with degrees of freedom adjusted according to Wang (1971). All tests in each group were then combined. "Indicates significant difference between means for milo and pea, $p<.001$.

size as the average diameters of the two seed types. Examination of the gape means for individual subjects showed that all subjects increased beak opening with pea reinforcers, and these differences were statistically significant for eight of nine subjects. Although with each type of reinforcer there were slight differences between the conditioning group means, none of these differences was statistically significant.

\section{Discussion}

The major finding of Experiment 2 was that experience with a particular reinforcer results in a reinforcer-

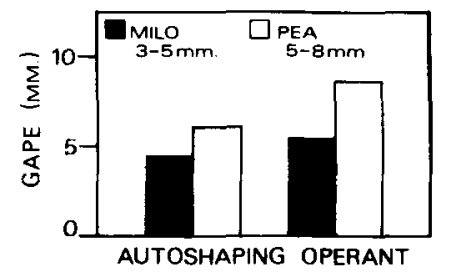

Figure 6. Conditioning group means for gape size obtained with either milo $(3-5 \mathrm{~mm})$ or pea $(5-8 \mathrm{~mm})$ reinforcers. appropriate beak opening for conditioned keypecks. Not only were qualitative differences between reinforcers (food vs. water) reflected in keypeck gape; means for gape corresponded to different sizes of seeds used as reinforcers as well. Thus, the adjustment of gape size to seed size seen for feeding responses appears to have a counterpart in conditioned keypecks with seed reinforcers. This finding extends those reports of a resemblance between conditioned and consummatory behavior (e.g., H. Jenkins \& Moore, 1973; Wolin, 1968; Woodruff \& Williams, 1976) and suggests the operation of a sensorimotor adjustment of keypeck beak opening that is determined by the size of seeds previously ingested as reinforcers. Comparable "anticipatory" effects upon other aspects of keypeck topography (force, duration) have been reported for pigeons maintained on a schedule of alternating food or water reinforcement (Spetch et al., 1981).

Since it has often been stressed that the physical properties of the conditioned stimulus must be considered for an adequate account of conditioned response form (Bindra, 1978; Jenkins \& Moore, 1973; Wasserman, 1981 ), it is perhaps surprising that stimulus features of the signal had such trivial effects relative to the influence of the reinforcer. However, the visual characteristics of the stimuli projected upon the response key did not exert reliable control over either gape size or peck location. The low percentage of pecks located on the circular stimuli indicates that pigeons have little inherent bias to respond preferentially to such visual features of conditioning signals. In this context, the greater percentage of pecks directed at the white circular stimuli than at the black ones may be explained as a tendency to peck at a more localized signal. With the white stimuli, the circular figure was the only signal; with the black stimuli, the signal included the background illumination of the entire key.

Since reinforcer delivery was never made contingent upon any specific orientation to the target stimuli, poor control of peck location by features of the conditioning signal may also be attributed to the conditioning procedures used. When such contingencies have been made explicit (e.g., Bugbee, 1979), accurate stimulus control of peck location has been achieved. Moreover, both H. Jenkins and Sainsbury (1970) and Goodale (1983) have reported that pigeons reliably direct pecks at stimulus features of conditioning signals when responding on a feature-positive discrimination task. In this procedure, the presence of a distinctive feature indicates positive trials on which responses will be rewarded. On negative trials, the signal lacks the positive feature and reward is unavailable. Thus, it appears that when pigeons must attend to the presence or absence of a feature, featuredirected pecking is obtained.

With regard to beak opening, it would be of interest to examine whether increased attention to stimulus features would promote a greater influence on keypeck gape. In the present experiments there was no specific 
contingency between emitted gape size and reinforcement imposed; nor did the circular stimuli provide any additional information concerning reinforcement. However, the failure to demonstrate a clear relationship between the size of a projected stimulus and keypeck gape is informative in view of our finding that properties of the reinforcer influence beak opening. During the sessions in which circular stimuli were projected on the response key as signals, either a small seed (milo) or water was used as the reinforcer. Despite substantial variation in the diameters of the circular stimuli, each reinforcer type produced relatively compressed ranges for gape size that were equivalent to those obtained with the plain signal. This suggests that the influence of the reinforcer in the determination of beak opening is not only rather precise but relatively dominant with respect to other features of the conditioning situation.

The absence of any major differences in the results obtained with the two conditioning procedures was problematic in view of the widely held conception that they involve different underlying associative processes. Autoshaping procedures have been shown to emphasize Pavlovian (response-independent) as opposed to operant (response-contingent) learning (for reviews see Schwartz \& Gamzu, 1977, and Terrace, 1981). Because of this distinction it has been suggested that the two procedures would produce different response topographies, and such differences have indeed been reported (e.g., Schwartz, 1977a, 1977b). However, in the present experiments the primary difference between the two procedures was in the contingency between the occurrence of a response and the delivery of a reinforcer; neither procedure placed specific requirements on the form of pecks to be produced. It is possible that the use of an omission procedure (Williams \& Williams, 1969) would produce more substantial differences in keypeck gape or location, but, while this procedure eliminates adventitious reinforcement of responding, it is not "uncontaminated" by response-dependent contingency. Since the omission procedure differs from the autoshaping procedure in that responses to the signal result in the elimination of the reinforcer for that trial, responses in the omission procedure are effectively punished by withholding an expected reward (negative punishment). Such a punishment contingency might also be expected to influence response topography (e.g., P. Jenkins, 1981), and so beyond the first response it could not be assumed that topography was unaffected by such response-dependent processes. It therefore appears that in the absence of specific contingencies regarding beak opening or peck location, similar factors establish these aspects of keypeck topography in either autoshaping or operant conditioning procedures.

\section{GENERAL DISCUSSION}

It is important to distinguish between those stimuli that elicit and/or orient a response and those that deter- mine the particular form of the movements (Hinde, 1970). For the pecking response, the effector systems producing the trajectory of the peck (neck and body musculature) and beak opening (jaw muscles) are discrete and the sensory processes controlling these aspects of the peck may be dissociated. Although pigeons must use visual cues to guide the peck to a specific location, our findings indicate that gape size was not determined solely by visual information (cf. Goodale, 1983; Zeigler et al., 1980). In both feeding and conditioning situations, gape appeared to be influenced by information provided during prior experience rather than having exclusive control by proximate visual stimuli. Moreover, the adjustment of keypeck-gape size to reinforcer size in the absence of any visual cues concerning seed size implies that control of gape must involve inputs from another sensory modality. Such an adjustment of beak opening requires the transformation of afferent sensory information concerning a physical variable (seed size) into variations in the output to jaw muscles controlling beak movements on subsequent pecks. An obvious candidate is the afference provided during grasping by somatosensory stimuli (tactile, proprioceptive) from the beak and jaw. Oral somatosensation therefore provides another major input for the control of grasping that could influence both conditioned and consummatory responses.

Recently, anatomical studies have identified a neural pathway which could mediate these aspects of the sensorimotor control of pecking in the pigeon. An afferent component of this pathway conveys somatosensory inputs from the oral region via the trigeminal nerves and terminates in an area of the telencephalon that receives visual inputs as well. This area of the telencephalon is also the origin of a descending pathway which has been homologized with the mammalian pyramidal tract and which terminates upon premotor neurons controlling beak movements (Berkhoudt, Klein, \& Zeigler, 1982; Wild \& Zeigler, 1980, 1982). Denervation and lesion experiments involving disruption of the afferent, efferent, or central components of this pathway have revealed a variety of pecking and grasping deficits related to the disruption of visual, somatosensory, and motor mechanisms (Levine \& Zeigler, 1981; Zeigler \& Karten, 1973; Zeigler, Miller, \& Levine, 1975).

An understanding of the factors controlling beak opening during pecking has significance because variations in gape characterize both conditioned keypecks and ingestive behaviors. The relationship between conditioned and unconditioned behaviors has had great importance for theoretical formulations of the conditioning process. The well-known generalization that the conditioned stimulus (CS) in Pavlovian conditioning evokes a conditioned response (CR) resembling that elicited by the unconditioned stimulus (UCS) provides the basis for the principle of stimulus substitution which makes the equivalence of conditioned and unconditioned responses explicit (Hilgard, 1936). H. Jenkins and Moore 
(1973) have proposed that "object substitution" might better describe the observation that the signal appears to act as a surrogate for the reinforcer in the autoshaping situation with pigeons. In a more recent view, it has been suggested that during ontogeny associative processes enable animals (pigeons) to direct consummatory fixed action patterns to appropriate stimuli and that the auto. shaping situation serves to redirect these innate patterns to the conditioning signal (Williams, 1981; Woodruff \& Starr, 1978; Woodruff \& Williams, 1976).

While such formulations have been of limited utility in the causal analysis of response form (Hinde, 1970; Zeigler et al., 1980), our results clearly provide evidence that the form of the response evoked by the conditioning signal was strongly influenced by characteristics of the reinforcer. The adjustment of gape size to seed size seen for feeding responses was comparable to the adjustment of keypeck gape found with different seed reinforcers. For both feeding and conditioned responses, there were indications that this adjustment of gape depended upon somatosensory information obtained from previous pecks, suggesting that the basis for this similarity of responses may be the operation of a common sensorimotor mechanism involving oral somatosensory stimuli. Selective potentiation during conditioning of the sensorimotor systems mediating the unconditioned response (UCR) has been a feature of many theories that wished to provide a neural representation of response facilitation that would account for the CS eliciting responses previously attributed to the UCS (e.g., Bindra, 1972; Pavlov, 1927). In the present case, both conditioned and consummatory pecks employ the same effector structures (e.g., beak, jaw muscles producing beak movements, neck musculature, etc.), and we contend that the operation of a common sensorimotor neural mechanism for the control of beak opening may account for the observed similarity of conditioned and consummatory responses.

This conclusion would indicate that, at least for this aspect of the conditioned pecking response, the relevant UCS is oral somatosensory stimuli provided during ingestion. Woodruff and Williams (1976) have also emphasized the role of oral somatosensory stimuli in their studies of conditioned response form. In their autoshaping experiments, visual stimuli related to the reinforcer were eliminated completely through direct injection of water into the mouth as reinforcement. This procedure provided only an association between the lighted key and intraoral water stimuli (somatosensory) and yet produced signal-directed keypecking that was reported to be qualitatively similar to drinking responses. Our results are consistent with such descriptions of the water-reinforced keypeck and indicate that the extent of beak opening provides a reliable indication of the type of reinforcer received.

It should be noted, however, that a particular keypeck topography is not simply determined by the most recent ingestion experience. Several autoshaping experiments (H. Jenkins \& Moore, 1973; Spetch et al., 1981) involving presentations of both food and water have shown that pigeons' keypeck topography may switch between the motor patterns appropriate for feeding and drinking on successive trials. Therefore, rather than having persistent effects on all subsequent responses, stimuli produced during ingestion are apparently associated with a specific $\mathrm{CS}$ as a result of the signal-reinforcer relation and may influence only responses to that CS.

The pigeon's pecking behavior has been one of the most exhaustively studied response systems in contemporary psychology, and yet only recently have studies begun to elucidate its neural control. The present behavioral findings indicate some elements of behavior theory that may soon be reconciled with physiological substrates. With this prospect, the pigeon's keypeck should continue to be a useful model system for the study of sensorimotor, motivational, and associative processes.

\section{REFERENCES}

Bezcher, W. J. (1951). Adaptations for food getting in American blackbirds. Auk, 68, 411-440.

Berkhoudt, H., Klein, B., \& Zeigler, H. P. (1982). Afferents to the trigeminal facial motor nuclei in the pigeon (Columba livia): Central connections of jaw motoneurons. Journal of Comparative Neurology, 209, 301-312.

Bindra, D. (1972). A unified account of classical conditioning and operant training. In A. H. Black \& W. F. Prokasy (Eds.), Classical conditioning. II: Current research and theory. New York: Appleton-Century-Crofts.

Bindra, D. (1978). How adaptive behavior is produced: A perceptual-motivational alternative to response-reinforcement. $B e$ havioral and Brain Sciences, 1, 41-52.

Blough, D. (1961). Experiments in animal psychophysics. Scientific American, 105, 113-122.

BugBee, N. M. (1979). The basal ganglia-tectal pathway: Its role in visually guided behavior in the pigeon (Columba livia). Unpublished doctoral dissertation, University of Maryland.

Goodale, M. A. (1983). Visually guided pecking in the pigeon (Columba livia). Brain, Behavior and Evoluton, 22, 22-41.

Grizzle, J. E., Starmer, C. F., \& Косh, G. G. (1969). Analysis of categorical data by linear models. Biometrica, 25, 489-504.

Hilgard, E. (1936). The nature of the conditioned response: 1 . The case for and against stimulus-substitution. Psychological Review, 43, 366-385.

HINDE, R. (1970). Animal behaviour: A synthesis of ethology and comparative psychology (2nd ed.). New York: McGraw-Hill.

Jenkins, H., \& Moore, B. (1973). The form of the autoshaped response with food or water reinforcers. Journal of the Experimental Analysis of Behavior, 20, 197-207.

Jenkins, H., \& Sainsbury, R. (1970). Discrimination learning with the distinctive feature on positive or negative trials. In D. I. Mostofsky (Ed.), Attention: Contemporary theory and analysis. New York: Appleton-Century-Crofts.

Jenkins, P. (1981). The determiners of keypeck duration. Animal Learning \& Behavior, 9, 501-507.

KLEIN, B., LAMon, B., \& Zeiglek, H. P. (1983). Drinking in the pigeon (Columba livia): Topography and spatiotemporal organization. Journal of Comparative Psychology, 97, 178-181.

LeVine, R., \& Zeigler, H. P. (1981). Extratelencephalic pathways and feeding behavior in the pigeon. Brain, Behavior and Evolution, 19, 56-92.

MitTelstaedt, H. (1962). Control systems of orientation in insects. Annual Review of Entomology, 7, 177-198.

Moore, B. (1973). The role directed Pavlovian reactions in simple instrumental learning in the pigeon. In R. A. Hinde \& J. A. 
Hinde (Eds.), Constraints on learning. London: Acadernic Press. Pavlov, I. P. (1927). Conditioned reflexes. New York and London: Oxford University Press.

ScWARTz, B. (1977a). Studies of operant and reflexive key pecks in the pigeon. Journal of the Experimental Analysis of Behavior, 27, 301-313.

SchwaAtz, B. (1977b). Two types of pigeon key pecking: Suppression of long but not short-duration key pecks by duration dependent shock. Journal of the Experimental Analysis of Behavior, 27, 363-378.

Schw ARTz, B., \& Gamzu, E. (1977). Pavlovian control of operant behavior: An analysis of autoshaping and its implications for operant conditioning. In W. K. Honig \& J. E. R. Staddon (Eds.), Handbook of operant behavior. Englewood Cliffs, NJ: Prentice-Hall.

Spetch, M., Wilkie, D., \& Skelton, R. (1981). Control of pigeons' keypecking topography by a schedule of alternating food and water reward. Animal Learning \& Behavior, 9, 223-229.

TERRACE, H. S. (1981). Autoshaping and two-factor learning theory. In C. M. Locurto, H. S. Terrace, \& J. Gibbon (Eds.), Autoshaping and conditioning theory. New York: Academic Press.

WANG, Y. Y. (1971). Probabilities of the type I errors of the Welch tests for the Behrens-Fisher problem. Journal of the American Statistical Association, 66, 605-608.

Wasserman, E. (1981). Response evocation in autoshaping: Contributions of cognitive and comparative-evolutionary analyses to an understanding of directed action. In C. M. Locurto, H. S. Terrace, \& J. Gibbon (Eds.), Autoshaping and conditioning theory. New York: Academic Press.

WiLD, M., \& Zeiglen, H. P. (1980). Central representation and somatotopic organization of the jaw muscles within the facial and trigeminal nuclei of the pigeon (Columba livia). Journal of Comparative Neurology, 192, 175-201.

Wild, M., \& Zeigler, H. P. (1982). Central control of eating in the pigeon: A sensorimotor chain from grain through brain. Society for Neuroscience Abstracts, 8, 612 .

Willi ams, D. (1981). Biconditional behavior: Conditioning with- out constraint. In C. M. Locurto, H. S. Terrace, J. Gibbon (Eds.), Autoshaping and conditioning theory. New York: Academic Press.

Williams, D., \& Williams, H. (1969). Auto-maintenance in the pigeon: Sustained pecking despite contingent non-reinforcement. Journal of the Experimental Analysis of Behavior, 12, 511-520.

Wolin, B. (1968). Difference in manner of pecking a key between pigeons reinforced with food and water. In A. C. Catania (Ed.), Contemporary research in operant behavior. Glenview, IL: Scott, Foresman.

WoonnufF, G., \& Starr, M. (1978). Autoshaping of initial feeding and drinking reactions in newly hatched chicks. Animal Learning \& Behavior, 6, 265-272.

WoodrufF, G., \& Williams, D. (1976). The associative relation underlying autoshaping in the pigeon. Journal of the Experimental Analysis of Behavior, 26, 1-13.

ZEIGLER, H. P. (1976). Feeding behavior in the pigeon. In J. S. Rosenblatt, R. A. Hinde, E. Shaw, \& C. Beer (Eds.), Advances in the study of behavior (Vol. 7). New York: Academic Press.

ZEIGLER, H. P., \& KARTEN, H. (1973). Brain mechanisms and feeding in the pigeon: Quinto-frontal structures. Journal of Comparative Neurology, 152, 59-82.

Zeigler, H. P., LevitT, P., \& Levine, R. (1980). Eating in the pigeon (Columbia livia): Movement patterns, stereotypy, and stimulus control. Journal of Comparative and Physiological Psychology, 94, 783-794.

Zeiglen, H. P., Miller, M., \& Levine, R. (1975). Trigeminal nerve and eating in the pigeon: Neurosensory control of the consummatory response. Journal of Comparative and Physiological Psychology, 89, 845-858.

ZwEers, G. (1982a). Drinking of the pigeon (Columba livia L.). Behaviour, 80, 274-317.

ZweErs, G. (1982b). Pecking of the pigeon (Columba livia L.). Behaviour, 81, 173-230.

(Manuscript received November 22, 1983; revision accepted for publication February $14,1984$. ) 